- There is little scientific basis for treatment standards for patients with coagulopathies.

- The medical history is critical to the identification of patients at risk for prolonged bleeding.

- Laboratory tests ordered must be specific to the specific bleeding disorder.

- The relationship between oral bleeding and liver, kidney and bone marrow disease is poorly understood.

- There is a need for research on the dental management of patients with coagulopathies.

\title{
Dental management considerations for the patient with an acquired coagulopathy. Part 1: Coagulopathies from systemic disease
}

\author{
P. B. Lockhart ${ }^{1}$, J. Gibson² ${ }^{2}$ S. H. Pond ${ }^{3}$ and J. Leitch ${ }^{4}$
}

\begin{abstract}
Current teaching suggests that many patients are at risk for prolonged bleeding during and following invasive dental procedures, due to an acquired coagulopathy from systemic disease and/or from medications. However, treatment standards for these patients often are the result of long-standing dogma with little or no scientific basis. The medical history is critical for the identification of patients potentially at risk for prolonged bleeding from dental treatment. Some time-honoured laboratory tests have little or no use in community dental practice. Loss of functioning hepatic, renal, or bone marrow tissue predisposes to acquired coagulopathies through different mechanisms, but the relationship to oral haemostasis is poorly understood. Given the lack of established, science-based standards, proper dental management requires an understanding of certain principles of pathophysiology for these medical conditions and a few standard laboratory tests. Making changes in anticoagulant drug regimens are often unwarranted and/or expensive, and can put patients at far greater risk for morbidity and mortality than the unlikely outcome of postoperative bleeding. It should be recognised that prolonged bleeding is a rare event following invasive dental procedures, and therefore the vast majority of patients with suspected acquired coagulopathies are best managed in the community practice setting.
\end{abstract}

Dental patients often present with a medical history that suggests the potential for clinically significant intraoperative bleeding, which might be defined as blood obscuring the operative site and

This work was initiated while Dr. Lockhart was a TC White Visiting Professor at the Royal College of Physicians and Surgeons, and at Glasgow Dental Hospital and School, University of Glasgow, UK

${ }^{1}$ Chairman, Department of Oral Medicine, Carolinas Medical Center, Charlotte, North Carolina, 28232 USA; ${ }^{2}$ Senior Lecturer and Honorary Consultant in Oral Medicine

${ }^{4}$ Clinical Lecturer in Oral Surgery and Sedation, Glasgow Dental Hospital \& School, 387 Sauchiehall Street, Glasgow G2 3JZ, Scotland; ${ }^{3}$ GDP, 510 Allen Street, Kelso, WA, USA *Correspondence to: Dr Peter B. Lockhart, Chairman, Department of Oral Medicine, Carolinas Medical Center, PO Box 32861, Charlotte, NC 28232-2861, USA

E-mail:Peter.Lockhart@carolinashealthcare.org

\section{Refereed Paper}

doi:10.1038/sj.bdj.4810593

Received 29.07.02; Accepted 04.02.03

$\odot$ British Dental Journal 2003; 195: 439-445 interfering with carrying out a given procedure, or blood loss sufficient to require transfusion. Several hours of minor postoperative bleeding is of little concern following procedures such as dental extractions, but there is no commonly accepted definition of what constitutes prolonged or clinically significant postoperative bleeding. It could be defined as that which:

1. Continues beyond 12 hours;

2. Causes the patient to call or return to the dental practitioner or to the accident and emergency department;

3. Results in the development of a large haematoma or ecchymosis within the oral soft tissues; or

4. Requires a blood transfusion.

Most episodes cause concern or inconvenience to the patient, and rarely require a return to the dental surgery or local accident and emergency department.

Coagulopathies that predispose to oral bleeding can be divided into two broad categories - inherited and acquired. This two part review covers acquired coagulopathies that arise from disease, or medications, or both. Disease-related bleeding disorders result most often from hepatic, renal, and bone marrow disorders, which have varying effects on the haemostatic process (Table 1). Bleeding problems from medications will be covered in a subsequent paper. An understanding of the basic features of the coagulation cascade is helpful for an appreciation of the common elements of inherited and acquired coagulopathies and how medications and disease affect the coagulation cascade (Fig. 1). ${ }^{1}$

The challenge for the dental practitioner is to: 


\begin{tabular}{|c|c|c|}
\hline Disease & Common causes & Resulting coagulopathy \\
\hline $\begin{array}{l}\text { Renal failure } \\
\text { and uraemia }\end{array}$ & $\begin{array}{l}\text { Diabetes mellitus } \\
\text { Glomerulonephritis } \\
\text { Pyelonephritis } \\
\text { Hypertension }\end{array}$ & $\begin{array}{l}\text { Inhibition of adhesion and primary } \\
\text { aggregation of platelets from glycoprotein } \\
\text { Ilb-Illa defect }\end{array}$ \\
\hline Hepatic failure & $\begin{array}{l}\text { Alcohol abuse } \\
\text { Hepatitis B and C } \\
\text { Cancer (eg hepatocellular } \\
\text { carcinoma) }\end{array}$ & $\begin{array}{l}\text { Obstructive jaundice - impedes Vit K } \\
\text { delivery to the liver - loss of factors II, } \\
\text { VII, IX,X } \\
\text { Loss of hepatic tissue and all clotting } \\
\text { factors except VIII and von Willebrand } \\
\text { factor }\end{array}$ \\
\hline $\begin{array}{l}\text { Bone marrow } \\
\text { failure }\end{array}$ & $\begin{array}{l}\text { Alcohol abuse } \\
\text { Cancer (eg leukemia) } \\
\text { Myelosuppressive } \\
\text { medications (eg cancer } \\
\text { chemotherapy) } \\
\text { Uraemia from renal failure }\end{array}$ & $\begin{array}{l}\text { Reduced number of functioning platelets } \\
\text { Anaemia from bone marrow suppression }\end{array}$ \\
\hline
\end{tabular}

1. Determine the relative likelihood of clinically significant bleeding from a variety of invasive procedures for patients with liver, kidney, or bone marrow disorders; and

2. Put into perspective the risk for, and outcome of, clinically significant bleeding versus the risk associated with altering the patient's medical management (eg anticoagulant dosage).

This issue becomes more complex and even less science-based when a patient has more than one source of a coagulopathy, such as the chronic alcoholic who takes an anticoagulant for cardiovascular disease.

Community practice standards are based on a large volume of chapters, case reports, retrospective studies, opinion papers, and unofficial guidelines, few of which are based on data from clinical trials. The ordering of laboratory tests and making changes in anticoagulant drug regimens are often unwarranted and/or expensive, and can put patients at far greater risk for morbidity and mortality than the unlikely outcome of postoperative bleeding. The dental management of these patients is less complicated than commonly thought, and can usually be accomplished in the primary care setting without the need for changes in medical management, referral to a specialist, or hospitalisation., ${ }^{2,3}$

This paper summarises common acquired coagulopathies due to systemic disease, and proposes guidelines for the evaluation and management of this often-challenging group of patients. The process of patient management begins with the medical and dental history and an assessment of the need for medical consultation and laboratory studies.

\section{THE MEDICAL HISTORY}

The appropriate medical history is dictated by the clinical situation, and is a prerequisite for the proper management of all dental patients, in particular those who may be at risk for oral bleeding. Information gained from the patient will usually suggest the nature and severity of the coagulopathy, and this may be all that is needed prior to an invasive dental procedure. Standard medical history questionnaires can be used to gather preliminary information as a starting point for a more focused verbal questioning. Such screening forms should have questions concerning current and past problems with kidneys, liver, bone marrow, malignant disease, and the use of specific medications thought to cause a coagulopathy. Some patients will have difficulty completing history forms due to a poor understanding or expression

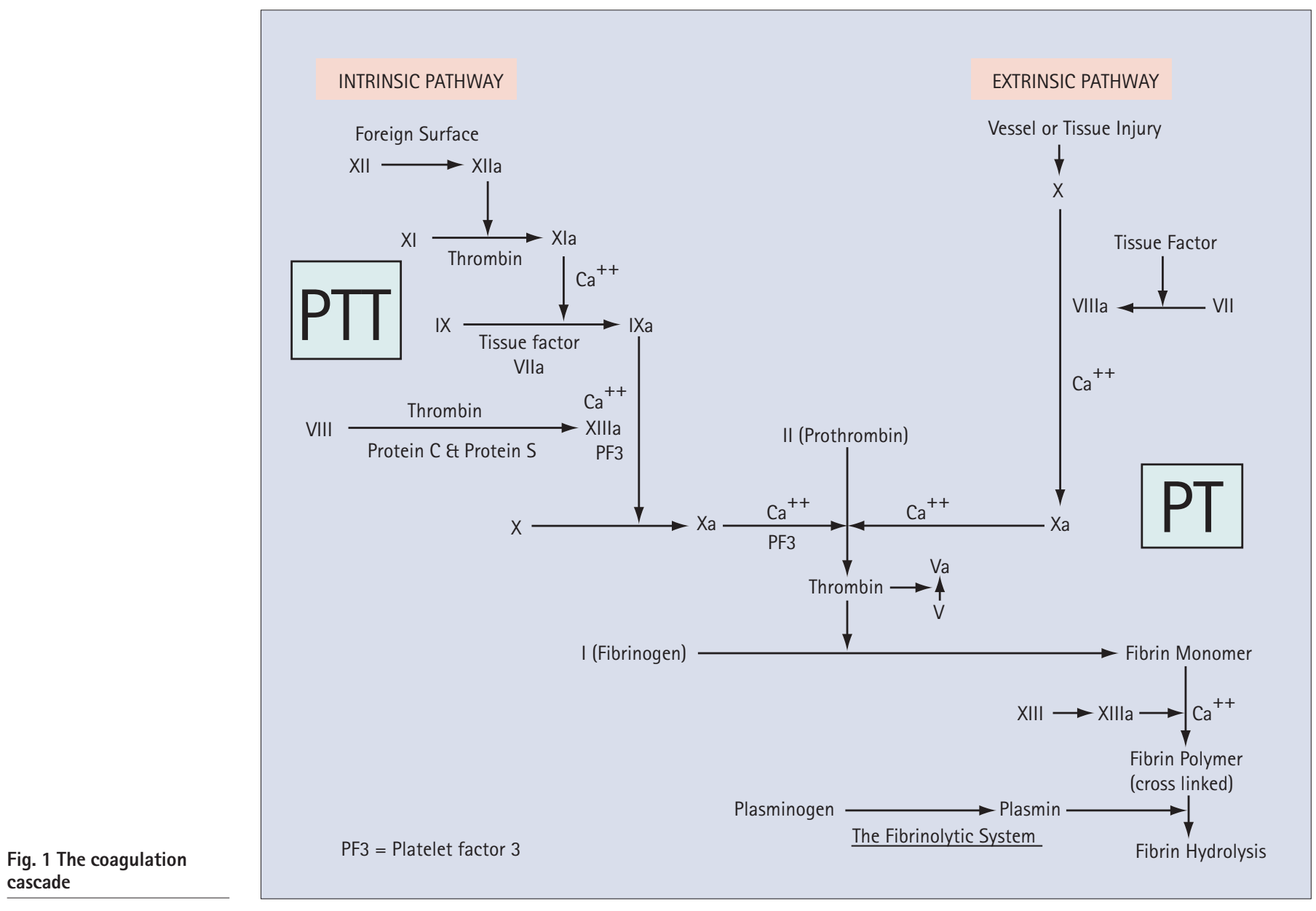


of written English. It should be remembered that the illiteracy rate in the UK is higher in some areas, than others.

When patients give a history suggestive of abnormal bleeding, the following issues should be resolved:

1. Does the bleeding episode meet at least one of the criteria mentioned above for clinically significant postoperative bleeding?

2. Was it due to local factors such as preexisting infection, localised trauma, rinsing, spitting, or smoking cigarettes; or was it spontaneous, which is rare but might represent a clotting disorder of systemic origin?

3. If it suggests a systemic bleeding disorder, does it represent an acquired (eg drug related) or inherited coagulopathy?

4. Does it suggest a coagulopathy with one or more causes?

Although pre-existing infection is reported to be the most common cause of an isolated episode of prolonged bleeding following tooth extraction, patients must be fully questioned regarding the circumstances. ${ }^{4}$ The following specific points in the medical history should alert the practitioner to a potential problem:

1. Previous diagnosis of a bleeding tendency (eg epistaxis (nose bleed), easy bruising);

2. Prolonged bleeding after nondental surgical procedures (eg tonsillectomy);

3. Bleeding lasting more than 24 hours or requiring a transfusion;

4. Hospital attendance and/or admission for postoperative bleeding;

5. Use of medications known to interfere with coagulation (eg warfarin);

6. Bleeding that begins some days after the procedure (eg haemophilia); and

7. Chronic and excessive alcohol intake (record type, volume consumed/week, and duration in years). Although it can be a difficult subject, it is important to know about the volume of alcohol consumed per week and the duration in years. Heavy alcohol consumption is a common cause of coagulopathy, ${ }^{5}$ and it can be enhanced by the use of over-thecounter medications (eg NSAIDs).

A positive response to any of the above questions should lead the dental practitioner to pursue further details until a decision can be made regarding the need for laboratory testing and medical consultation, or a determination that there is no reason for concern. ${ }^{6}$ Each individual coagulopathy, whether from medication or systemic disease, dictates specific questions and medical evaluation (eg laboratory tests) to determine nature and severity. A more significant problem arises if there are multiple coagulopathies. Although single coagulopathies rarely result in clinically significant oral bleeding, multiple coagulopathies must be evaluated individually and then be considered together, as two relatively insignificant coagulopathies can result in prolonged intra- or post-operative haemorrhage. Examples include:

1. Patients with chronic renal failure who takes aspirin and/or another anticoagulant for cardiovascular disease or hypercoagulability from nephrotic syndrome

2. Patients with alcoholism affecting both liver and bone marrow who take NSAIDs or another platelet inhibitor as prophylaxis for coronary artery disease.

In addition to the medical history, the clinical examination of the oral mucosa may reveal signs of an undiagnosed bleeding disorder. For example, ecchymosis (superficial bleeding under the mucosa) and haematomas (a mass of extravasated blood under the mucosa) suggest a coagulopathy, especially in the absence of trauma. Petechiae (small hemorrhagic spots under the mucosa) and prolonged bleeding from minor wounds suggest a problem with platelets (quantitative or qualitative) or with blood vessel integrity.

\section{LABORATORY STUDIES}

Specific laboratory tests are often recommended to help determine the potential for prolonged bleeding from surgical procedures in patients with hepatic, renal, and bone marrow disorders (Tables 2-4). Historically, the standard battery of laboratory tests included the bleeding time (BT), prothrombin time (PT), partial thromboplastin time (PTT), platelet count, and International Normalised Ratio (INR). The INR and PTT will be discussed in a companion paper, as they relate primarily to coagulopathies from warfarin and heparin respectively. Other tests, such as blood urea, serum creatinine, creatinine clearance, haemoglobin, serum albumin, and bilirubin are commonly thought to be of some value, but they have limited use in dental practice because cut-off values for safe treatment have not been established. Laboratory screening tests helpful in the evaluation of patients with renal, liver or bone marrow disease who may be at risk for bleeding are:

\section{Bleeding time test}

The standard method of determining platelet function is to use one of the technique-sensitive bleeding time (BT) tests. Refinements in the technique of performing a BT since it was first described in 1910 have resulted in a test that is often used as a preoperative screen for the potential for bleeding. The template BT test involves applying a blood pressure cuff to the arm and making a standardised incision on the forearm with a template (small blade). The wound is then carefully blotted on a specific schedule, and the time it takes for the bleeding to stop is recorded in minutes. One hospital reported that over 1,900 preoperative BTs were ordered in a 6-month period for patients felt to be at risk for bleeding, $6 \%$ of which were abnormal. ${ }^{7}$ It has been estimated that the misuse of the BT test in the Unites States results in a cost of 114 million dollars (about 75 million pounds sterling) each year. ${ }^{8}$ Abnormally long bleeding time test results can have several causes, such as abnormal skin and vascular tone, thrombocytopenia, acquired abnormalities of platelet function (eg aspirin use), fibrinolysis, anaemia, uraemia, liver disease, and von Willebrand factor deficiency, as well as errors in technique of performing this test. ${ }^{7,9-11}$ Although current

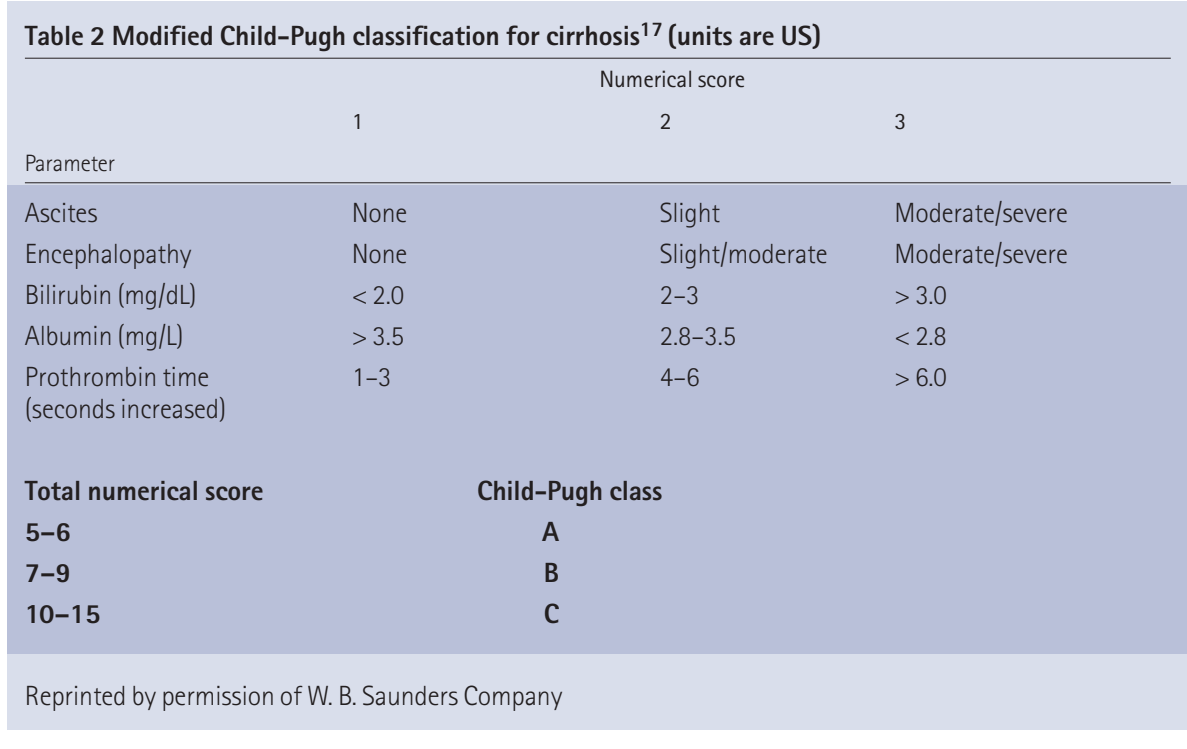




\section{PRACTICE}

\begin{tabular}{lll}
\multicolumn{3}{l}{ Table 3 Laboratory tests used for evaluation of coagulopathies from systemic disease } \\
\hline Test & Purpose & Normal range \\
\hline Prothrombin time (PT) & $\begin{array}{l}\text { Measure of extrinsic clotting cascade and } \\
\text { production of liver dependent clotting } \\
\text { factors }\end{array}$ & $10-13$ seconds \\
\hline $\begin{array}{l}\text { Quantitative assessment of circulating } \\
\text { platelets (eg leukemia, chemotherapy) }\end{array}$ & $150,000-450,000 / \mu l$ \\
$\begin{array}{l}\text { Creatinine clearance } \\
\text { (CRCL) }\end{array}$ & Determination of renal function & $90-125 \mathrm{ml} / \mathrm{min}$ \\
\hline Bilirubin (conjugated) & Determination of hepatic disease & $<0.3 \mathrm{mg} / \mathrm{dL}$ \\
Albumin & Chronic hepatic disease & $3.5-4.5 \mathrm{~g} / \mathrm{dL}$ \\
& & $(35-45 \mathrm{~g} / \mathrm{L})$
\end{tabular}

\begin{tabular}{|c|c|c|}
\hline Platelet count (per $\mu \mathrm{l}$ ) & Diagnosis & Effect \\
\hline $150,000-450,000$ & Normal & Unlikely cause of oral bleeding \\
\hline $100,000-150,000$ & Mild thrombocytopenia & $\begin{array}{l}\text { Potential increased oral bleeding from } \\
\text { invasive procedures, but rare }\end{array}$ \\
\hline $50,000-100,000$ & Moderate thrombocytopenia & $\begin{array}{l}\text { Increased incidence of oral bleeding from } \\
\text { procedures possible, but uncommon }\end{array}$ \\
\hline \multirow[t]{2}{*}{$25,000-50,000$} & Severe thrombocytopenia & $\begin{array}{l}\text { Problematic bleeding (even with } \\
\text { venepuncture) }\end{array}$ \\
\hline & & $\begin{array}{l}\text { Elective invasive procedures should be } \\
\text { deferred }\end{array}$ \\
\hline \multirow[t]{2}{*}{$<25,000$} & Life threatening & $\begin{array}{l}\text { Spontaneous bleeding possible (usually } \\
<10,000 \text { ) }\end{array}$ \\
\hline & & $\begin{array}{l}\text { Only emergency invasive procedures and } \\
\text { with haematology involvement }\end{array}$ \\
\hline
\end{tabular}

standard of care suggests that the use of a BT test and its correlations with postoperative bleeding at non-oral sites, applies to invasive dental procedures, ${ }^{12}$ there are no prospective studies to confirm this. The BT test is not normally performed in the UK, and there is no clear indication for its use in community dental practice.

\section{Prothrombin time}

The presurgical prothrombin time (PT) is an example of a time-honoured laboratory test commonly used to evaluate patients with liver disease, as it measures extrinsic pathway factors (I, II, V, VII, X), three of which (II, VII, X) are vitamin K dependent (Fig. 1). This test is performed by mixing calcium and thromboplastin with citrated plasma and measuring the time it takes to coagulate. Thromboplastin is a phospholipid-protein extract of animal tissues that contains the tissue factor and the phospholipid necessary to provide the activation of factor X by factor VII. ${ }^{13}$ In the past this test was not standardised, as different commercially-produced thromboplastins were used throughout the world. This resulted in varying degrees of anticoagulation, even with identical PTs. Nevertheless, the PT test is useful to estimate the degree of liver damage and the propensity for bleeding, keeping in mind that it is not a linear relationship. A large portion of the liver (around 30-50\%) must be destroyed to be reflected in an elevated PT test result, and therefore a slightly increased PT test likely represents significant liver damage.

\section{Platelet count}

The platelet count is a measure of the number of platelets in the systemic circulation, with a normal range of 150,000-450,000/ $\mu \mathrm{l}$ (Table 3). A low platelet count (thrombocytopenia) can result from destruction (eg drug poisoning from alcohol, hypersplenism from liver disease) or a decreased production (eg leukaemia, drugs). Although this test gives little or no information concerning the viability or functionality of platelets, there are generally accepted platelet count ranges that represent varying degrees of thrombocytopenia and risk for bleeding (Table 4). Certain drugs and systemic disease can affect platelets both quantitatively and qualitatively, as discussed under specific diseases above.

\section{Creatinine, blood urea, and creatinine clearance tests}

Although the creatinine and blood urea tests give a measure of impaired renal function, they are not useful in dental practice as it is not known what test results represent a clinically significant risk for oral bleeding. ${ }^{14,15}$ A creatinine of 265-355 $\mu \mathrm{mol} / \mathrm{L}$ suggests the possibility of a problem, but at 530-620 $\mu \mathrm{mol} / \mathrm{L}$ the likelihood of prolonged oral bleeding becomes a concern. Creatinine clearance (CRCL) test is often cited as a gold standard for the degree of renal failure, but test results may be inaccurate due to the common (20\%-30\%) problem of an incomplete 24-hour urine collection.

The CRCL test could serve as a rough predictor for prolonged oral bleeding, although there are no prospective studies to demonstrate this relationship. Patients with a potential for oral bleeding would likely have calculated CRCL values of less than $20 \mathrm{~mL} / \mathrm{min}$. In addition, the relationship between CRCL and the degree of renal failure is not linear, since a change from 1 to 2 on the CRCL severity scale can indicate a 50\% decline in renal function. However, the difficulty of acquiring an accurate CRCL test result precludes its use in community dental practice.

\section{COAGULOPATHY AS A CONSEQUENCE OF DISEASE:}

\section{Chronic renal failure}

Over 200,000 people in the United States have chronic renal failure (CRF) and a resultant uraemia necessitating dialysis. ${ }^{16}$ In the UK, more than 500 patients/million population are currently receiving treatment, consuming $2 \%$ of the NHS budget. ${ }^{17}$ Causes of CRF include diabetes mellitus, glomerulonephritis, and hypertension. Patients with CRF can be hypercoagulable due to depletion of proteins $\mathrm{C}, \mathrm{S}$, and antithrombin III. Haemostasis in patients with CRF is impaired principally as a result of an ill-defined platelet dysfunction from hyperviscosity and a defect in platelet membrane glycoproteins (gp IIb-IIIa), which play an important role in the adhesion and primary platelet aggregation stages of haemostasis (Table 1). ${ }^{18-21}$ These glycoproteins serve as platelet membrane receptor sites for binding fibronectin and von Willebrand factor, which are necessary for their proper function. ${ }^{20,22}$ The bleeding time test result can be elevated in uraemic patients with CRF in accordance with this platelet defect, although this can be related to anaemia as well. ${ }^{23}$ However, platelet function is also increased in the setting of nephrotic hyperproteinaemia (increased protein in the blood) from kidney failure, and platelet aggregation inhibitors (eg lowdose aspirin) are often prescribed. ${ }^{24}$ The kidneys are also a major source of erythropoietin, a key cytokine that induces myeloid stem cells in the bone marrow to differentiate into mature red cells.

Patients with CRF will either be in a predialysis state or they will be on a regular dialysis programme. The determination of when dialysis patients have the potential for clinically significant bleed- 
ing from dental surgery is usually straightforward, since they should not be in a uraemic state following dialysis, and therefore should not have problems with platelet function. However, individuals with renal failure, but not yet on dialysis are more difficult to evaluate. Although kidney function is monitored by the blood urea, creatinine, and creatinine clearance laboratory tests, it is not known what these laboratory values must be to represent a clinically significant risk for oral bleeding. Finally, given the increased incidence of hypertension in this patient population, mean blood pressure should be factored into the assessment of the potential for prolonged bleeding.

\section{Hepatic failure}

Hepatitis, hepatic cancer (primary or secondary), cirrhosis secondary to alcohol abuse, and other diseases that destroy liver tissue and decrease hepatic protein synthesis, (except factor VIII and von Willebrand factor) all result in a decrease in the clotting factors necessary for haemostasis (Table 1). ${ }^{25-27}$ In addition, obstructive jaundice from cholestasis impedes Vitamin $\mathrm{K}$ absorption, thus interfering with the production of the Vitamin K-dependent factors II, VII, IX, and X, and proteins C and S. ${ }^{28}$ Cirrhosis and portal hypertension can also lead to an increased bleeding time, as liver disease interferes with platelet distribution and results in hypersplenism and folate deficiency.

Liver function laboratory tests are used to determine liver disease status, but there is no definitive laboratory test that determines the degree of hepatic failure, such as the creatinine clearance test serves for renal disease. Liver disease, if severe enough, will manifest as an elevated prothrombin time (PT) test result, but the correlation between PT test results and oral bleeding has not been established. Attempts have been made to use a variety of laboratory test values and physical findings to determine risk for bleeding, and the Child-Pugh classification scheme is the most common. More recently, the modified Child-Pugh classification for cirrhosis has been described (Table 2). ${ }^{26}$ This scheme uses ascites (increased abdominal girth from fluid retention), encephalopathy (from buildup of proteins in the blood), bilirubin, albumin, and prothrombin time test results to arrive at a numerical score. The value of this scheme as a predictor of bleeding following dental surgery has not been determined, but it is unlikely that bleeding would occur with a Modified Child Pugh result of A or B, as Category B patients would rarely have a PT greater than 4 seconds over the control value.

\section{Bone marrow failure}

There are several causes for the loss of haemopoietic bone marrow cells (Table 1). For example, the abnormal line of malignant cells in leukaemia can suppress production of normal blood cells, and the result could be oral (gingival) bleeding as the first indication of promyelocytic leukaemia. Some cancer chemotherapy agents target specific progenitor cells in the marrow (eg leukaemic cells), and others suppress all bone marrow cells, to include platelets. The most important outcome of bone marrow failure or damage, from the standpoint of oral bleeding, is the impact on megakaryocytes, the progenitor cells for platelets. Uraemia from renal failure and chronic alcohol ingestion can damage the bone marrow, and results in low platelet counts and an interference with platelet function.

There are other diseases and conditions that predispose to oral bleeding, but they are either rare (eg aplastic anaemia) and/or their nature may preclude invasive dental procedures in the community setting without medical consultation. Malnutrition can cause a vitamin $\mathrm{K}$ deficiency that results in prolonged bleeding, and prolonged vitamin C deficiency will produce scurvy, a rare but life threatening disorder that presents with gingival swelling and bleeding.

\section{DENTAL MANAGEMENT CONSIDERATIONS}

\section{Fundamentals in patient management}

In most situations of a single coagulopathy, extractions and other similarly invasive procedures can be managed safely in a community dental practice. Careful surgical technique, including an attempt at primary wound closure and local haemostatic measures will usually suffice. Oxidised cellulose tranexamic acid rinses, ${ }^{29-31}$ astringents (eg aluminum chloride), microfibrillar collagen, thrombin-soaked gauze, ${ }^{32}$ fibrin sealant and adhesive, ${ }^{2,33}$ electrocautery, ${ }^{32}$ absorbable gelatin sponges, and aminocaproic acid (EACA) to prevent clot lysis, have all been suggested as aids to haemostasis in this setting. ${ }^{3,34-39}$ Many of these methods are based on studies with flawed designs and therefore lack scientific validity. A study of 69 patients undergoing oral surgical procedures, with varying INR values from warfarin had no cases of clinically significant prolonged or excessive bleeding with the use of both absorbable gelatin sponges and fibrin sealant. ${ }^{2}$ However, prospective clinical studies suggest that a surgical sponge with or without sutures is all that is necessary. ${ }^{40}$ The usual concentrations of epinephrine in local anaesthetic (ie 1:80,000 in the UK) should also help with intra- and post-operative bleeding. In the case of single coagu- lopathies, moderately invasive procedures such as dental scaling, crown and bridge procedures, and uncomplicated dental extractions can be done safely without alteration of anticoagulant medications or preoperative blood transfusions. Patients with multiple or more severe single coagulopathies are best managed by dentists familiar with these disorders and in settings where blood products are available, should they become necessary. Medical advice should be sought for patients with the following situations:

1. Multiple coagulopathies;

2. Advanced uraemia without dialysis;

3. Platelet counts of less than 50,000 ;

4. Pre-liver transplant status;

5. Aplastic anaemia; and

6. High dose (ie myelosuppressive) cancer chemotherapy.

The fundamentals of the dental management of patients with coagulopathies are covered elsewhere. ${ }^{1,38,41}$ What follows are principles of patient management that relate to the underlying disease process, and which have varying scientific support.

The degree to which renal, hepatic, and bone marrow disease interfere with coagulation following invasive dental procedures is not well understood. Although we could find no randomised, prospective studies, it is unlikely that individuals whose renal failure is well managed with dialysis would be at increased risk for clinically significant bleeding, even from multiple dental extractions. However, patients with liver or bone marrow failure, and especially those with multiple coagulopathies, are at some risk. Therefore, patients with a medical history suggestive of a coagulopathy from systemic disease must be evaluated concerning the need to alter their dental management. Based on the medical history, patients may require specific laboratory tests, and consideration should be given to contacting the patient's medical practitioner, or if appropriate, a haematologist.

In the case of dialysis for CRF, patients are heparinised for the time they are receiving dialysis, and they could be anticoagulated to some degree for several hours thereafter. Heparinisation, along with chronic anticoagulation (eg aspirin, warfarin), creates a multifactorial coagulopathy that puts a patient at higher risk for bleeding from dental procedures immediately following dialysis. Although the halflife of heparin is approximately 4 hours, dialysis is a long and fatiguing procedure, and for this reason patients are better able to tolerate dental care on a non-dialysis day. On the other hand, the longer a patient is from their last dialysis, the more likely they are to have a coagulopathy from 
uraemia. Finally, use caution with drugs that are cleared by the kidneys, such as an increased plasma level of potassium from penicillin, as they can build up to toxic levels.

Patients with liver failure from any cause are difficult to evaluate from the standpoint of risk for oral bleeding. A relatively small elevation of the prothrombin time (PT) test (eg PT = 13-15) suggest significant (ie $>50 \%$ ) liver damage. There are various methods for improving patient tolerance of invasive procedures. Vitamin $\mathrm{K}$ (at doses of $10 \mathrm{mg}$ IM) corrects hypoprothrombinemia from malnutrition and biliary obstruction, but not intrinsic liver disease. Fresh frozen plasma will lower the prothrombin time, and platelet transfusion addresses both quantitative and qualitative problems. In the case of more significant coagulopathies, the approach to an invasive procedure may need to be adjusted accordingly, and the patient should be observed post-operatively in the surgery for a longer time period than usual. Care should be exercised with the use of narcotic analgesics (eg morphine) and sedatives (eg diazepam), as their duration is prolonged in decompensated liver disease. As with chronic renal failure, smaller doses should be used for drugs that are metabolised by the liver. In particular, avoid the use of paracetamol in the presence of liver failure and alcoholism, although doses of up to $4 \mathrm{~g} /$ day are allowable. Algorithms have been proposed for the determination of risk for bleeding from varying invasive procedures, but it is important to recognise that there are few if any reliable prospective studies to provide firm guidelines for these issues. ${ }^{38}$

Patients with bone marrow failure or damage, who do not have another coagulopathy, are of concern from the standpoint of their platelet status, both quantitative and qualitative. A platelet count test result should be above 50,000 for elective and moderately invasive procedures. Although most textbooks suggest a risk of bleeding with a platelet count below 50,000, in the absence of an additional coagulopathy, single tooth extractions can often be accomplished with counts below this level (eg > 30,000), but consultation with the patient's haematologist is advised.

\section{Risk from various dental procedures}

The risk of bleeding from various invasive dental procedures is a poorly understood area of clinical practice, and it forms a continuum of relative risk from none to great. It is clear that a simple restoration that does not involve the gingiva is non-invasive and poses little or no risk by comparison with deep scaling and multiple extractions. The difficulty lies in the middle ground of invasiveness, (eg supragingival scaling, extensive restorations). A long-standing concern exists with block injections as opposed to infiltration of local anaesthesia, since it requires deeper invasion of the tissues and the potential to invade muscle and large vessels. As a general rule, inferior dental block anaesthesia should be considered an invasive procedure, if only because of the long-standing (but poorly documented) concern about bleeding in an area that is difficult to control and which might involve the airway. A combination of infiltration and intraligamentary anaesthesia might be appropriate in cases of severe coagulopathy, but only for extractions or endodontic procedures, as permanent damage to the neurovascular contents of the pulp chamber could result from restorative procedures following intraligamentary injections. The spectrum of risks in each of these scenarios may never be fully established, but a combination of common sense, an understanding of the principles involved, clinical experience, and an ability to manage the rare complication of bleeding allow for the least risk to the patient.

Given the vascularity of the oral cavity, some degree of intra- and post-operative bleeding from surgical procedures is expected. However, the incidence of clinically significant intra- or post-operative bleeding following a single tooth extraction is unusual or rare. In addition to cost/benefit issues, dental practitioners should avoid the discomfort, inconvenience and expense of unnecessary laboratory testing, specialty referral, and/or hospitalisation. Few prospective clinical studies exist to aid in the determination of management protocols for patients with acquired coagulopathies, and therefore current clinical practice is often based on opinion, historical precedent, case reports, and false assumptions based on laboratory testing. ${ }^{36,42}$ Clearly, high-quality research in this area of dental practice is a high priority.

The authors would like to thank Philip C. Fox DDS, Charles H. Packman MD, Mack Mitchell MD, and George Hart MD for their help in reviewing this manuscript.

1. Patton $L L$, Ship J A. Treatment of patients with bleeding disorders. Dent Clin North Am 1994; 38: 465-482.

2. Bodner L, Weinstein J M, Baumgarten A K. Efficacy of fibrin sealant in patients on various levels of oral anticoagulant undergoing oral surgery. Oral Surg Oral Med Oral Pathol Oral Radiol Endod 1998; 86: 421-424.

3. Souto I C, Oliver A, Zuazu-Jausoro I, Vives A Fontcuberta J. Oral surgery in anticoagulated patients without reducing the dose of oral anticoagulant: $\mathrm{A}$ prospective randomized study. J Oral Maxillofac Surg 1996; 54: 27-32.

4. Seward G R, Harris M, McGowan D A, Killey H C, Kay L W. An Outline of Oral Surgery Parts I \& II. Oxford: Wright, 1998.

5. Friedlander A H, Mills M J, Gorelick D A. Alcoholism and dental management. Oral Surg Oral Med Oral Pathol 1987; 63: 42-46.

6. Lockhart PB, Schmidtke M A. Antibiotic considerations in medically compromised patients. Dent Clin North Am 1994; 38: 381-402.

7. Barber A, Green D, Galluzzo T, Ts'ao C. The bleeding time as a preoperative screening test. Am J Med 1985; 78: 761-764.

8. Rodgers R P C, Levin J. Bleeding time revisited (letter to the editor with response). Blood 1992; 79: 24952497.

9. Bowie E J W, Fass D N, Owen C A, Jr. Hemostatic effect of transfused Willebrand factor in porcine von Willebrand's disease. Similarities to the human disease. Haemostasis 1980: 9: 352-365.

10. Deykin D, Janson P, McMahon L. Ethanol potentiation of aspirin-induced prolongation of the bleeding time. NEng/ J Med 1982; 306: 852-854.

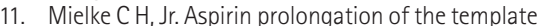
bleeding time: Influence of venostasis and direction of incision. Blood 1982; 60: 1139-1142.

12. Bashein G, Nessly M L Rice A L Counts R B, Misbach $G A$. Preoperative aspirin therapy and reoperation for bleeding after coronary artery bypass surgery. Arch Intern Med 1991; 151: 89-93.

13. Hirsh J, Poller L, Deykin D, Levine M, Dalen J E. Optimal therapeutic range for oral anticoagulants. Chest 1989; 95: 5S-11S.

14. NKF-DOQI Clinical Practice Guidelines for Hemodialysis Adequacy. 1997. New York: National Kidney Foundation. Ref Type: Pamphlet

15. Hakim R M, Depner T A, Parker T F, III. Adequacy of hemodialysis. Am J Kidney Dis 1992; 20: 107-123.

16. Pastan S, Bailey J. Dialysis therapy. N Engl J Med 1998; 338: 1428-1437.

17. Feest T. Epidemiology and causes of chronic renal failure. Savage C O S, Gaskin G, eds. Medicine - UK Edition 27[6], 30-32. 1999. London: England, The Medicine Publishing Company Ltd. Chronic Renal Failure. Feest, T. Ref Type: Serial (Book,Monograph)

18. Gawaz M P Dobos G, Spath M, Schollmeyer P. Gurland H J, Mujais S K. Impaired function of platelet membrane glycoprotein IIb-IIla in end-stage renal disease. J Am Soc Nephro/ 1994; 5: 36-46.

19. Benigni A, Boccardo P, Galbusera M, Monteagudo J, De Marco L, Remuzzi G et al. Reversible activation defect of the platelet glycoprotein Ilb-Illa complex in patients with uremia. Am J Kidney Dis 1993: 22: 668-676.

20. George J N, Shattil S J. The clinical importance of acquired abnormalities of platelet function. NEng/J Med 1991; 324: 27-39.

21. Sreedhara R, Itagaki I, Lynn B, Hakim RM. Defective platelet aggregation in uremia is transiently worsened by hemodialysis. Am J Kidney Dis 1995; 25 555-563.

22. Galbusera M, Benigni A, Paris S, Ruggenenti P, Zoja C Rossi C etal. Unrecognized pattern of von Willebrand factor abnormalities in hemolytic uremic syndrome and thrombotic thrombocytopenic purpura. J Am Soc Nephrol 1999; 10: 1234-1241.

23. Livio M, Marchesi D, Remuzzi G, Gotti E, Mecca G, de Gaetano G. Uraemic bleeding: role of anaemia and beneficial effect of red cell transfusions. Lancet 1982; November 6: 1013-1015.

24. Orth S R, Ritz E. The nephrotic syndrome. NEng/J Med 1998; 338: 1202-1211.

25. Cowan D H. Effect of alcoholism on hemostasis. Semin Hematol 1980; 17: 137-147.

26. Petruff CA, Chopra S. Cirrhosis and portal hypertension: An overview. In Friedman LS, Keeffe E B. Maddrey W C, eds. Handbook of Liver Disease.133. New York : Churchill Livingstone, 1998

27. Kessler D A. Drug promotion and scientific exchange. The role of the clinical investigator. NEng/ J Med 1991; 325: 201-203.

28. Landefeld C S, Beyth R J. Anticoagulant-related bleeding: clinical epidemiology, prediction, and prevention. Am J Med 1993: 95: 315-328.

29. Hurlen M, Erikssen J, Smith P, Arnesen H, Rollag A. Comparison of bleeding complications of warfarin and warfarin plus acetylsalicylic acid: a study in 3166 outpatients. J Intern Med 1994; 236: 299-304.

30. Sindet-Pedersen S, Ramström G, Bernvil S, Blombäck $M$. Hemostatic effect of tranexamic acid mouthwash 
in anticoagulant-treated patients undergoing oral surgery. N Engl J Med 1989; 320: 840-843.

31. Borea G, Montebugnoli L, Capuzzi P, Magelli C.

Tranexamic acid as a mouthwash in anticoagulanttreated patients undergoing oral surgery. An alternative method to discontinuing anticoagulant therapy. Oral Surg Oral Med Oral Pathol 1993; 75: 29-31.

32. Ziccardi V B, Saini J, Demas P N, Braun T W. Management of the oral and maxillofacial surgery patient with end-stage renal disease. J Oral Maxillofac Surg 1992; 50: 1207-1212.

33. Halfpenny W, Fraser J S, Adlam D M. Comparison of 2 hemostatic agents for the prevention of postextraction hemorrhage in patients on anticoagulants. Oral Surg Oral Med Oral Pathol Oral Radiol Endod 2001: 92: 257-259.

34. Vinckier F, Vermylen J. Blood loss following dental extractions in anticoagulated rabbits: Effects of tranexamic acid and socket packing. Oral Surg Oral Med Oral Pathol 1985; 59: 2-5.

35. White R H, McKittrick T, Takakuwa J, Callahan $C_{\text {, }}$ McDonell M, Finn S et al. Management and prognosis of life-threatening bleeding during warfarin therapy. Arch Intern Med 1996; 156: 1197-1201.

36. Martinowitz U, Mazar A L, Taicher S, Varon D, Gitel S $\mathrm{N}$, Ramot B et al. Dental extraction for patients on ora anticoagulant therapy. Oral Surg Oral Med Oral Pathol 1990; 70: 274-277.

37. Mulligan $R$, Weitzel K G. Pretreatment management of the patient receiving anticoagulant drugs. J Am Dent Assoc 1988; 117: 479-483.

38. Herman W W, Konzelman J L, Sutley S H. Current perspectives on dental patients receiving coumarin anticoagulant therapy. J Am Dent Assoc 1997; 128: 327-335.
39. Johnson W T, Leary J M. Management of dental patients with bleeding disorders: Review and update Oral Surg Oral Med Oral Pathol 1988; 66: 297-303.

40. Blinder D, Manor Y, Martinowitz U, Taicher S. Dental extractions in patients maintained on continued oral anticoagulant. Comparison of local hemostatic modalities. Oral Surg Oral Med Oral Pathol Oral Radio Endod 1999; 88: 137-140.

41. Surgical management of the primary care dental patient on warfarin. 2001. Liverpool, England, North West Medicines Information Centre. Ref Type: Generic

42. Rooney T P. General dentistry during continuous anticoagulation therapy. Oral Surg Oral Med Oral Pathol 1983; 56: 252-255. 